\title{
Александр ШУМИЛИН
}

\section{ФРАНЦИЯ: РЕСПУБЛИКА ПРОТИВ «ПОЛИТИЧЕСКОГО ИСЛАМА» (ЧАСТЬ II)}

\begin{abstract}
Аннотация. С 30 марта по 12 апреля 2021 г. члень французского Сената рассматривали подготовленный правительством проект закона о «противодействии сепаратизму». Его идеология в первую очередь нацелена на пресечение возросшей активности сторонников «политического ислама» (исламизма) на территории Франции. Ранее, 16 февраля 2021 г., документ был одобрен Начиональным собранием (нижней палатой парламента). Как показано в первой части статьи ${ }^{l}$, обсуждение проекта углубило раскол в мусульманском сообществе Франции на сторонников умеренного ислама, поддержавиих усилия правительства, и исламистов, отвергших основные положения документа. В данной статье сделана попытка анализа новой стадии отношений между государством и мусульманской общиной страны на фоне принятых сенаторами решений. Обвиняя правительство Франции в «исламофобии», исламские радикаль апеллируют к руководству Евросоюза. За ними отчётливо просматривается фигура турецкого президента Р.Т. Эрдогана, который всё активнее использует конфликты на религиозной почве в Европе в своих политических изеля. Автор статьи приходит к выводу о том, что обостряюшееся противостояние в мусульманской среде и вокруг неё приобретает во Франичи всё более очевидный политический подтекст.
\end{abstract}

Ключевые слова: Франция, мусульмане, ислам, политический ислам, Турция, Саудовская Аравия, Эрдоган, Макрон, Хартия принцииов, Дарманин.

Дебаты в Сенате, где преобладают политики правого толка, ещё больше повысили градус противостояния по вопросу о роли и месте ислама во французском обществе. Оно стремится сохранить и укрепить свои базовые принципы «свободы, равенства и братства» на основе светскости (отделения религии и церкви от государства). С различными направлениями христианства этот вопрос давно и основательно решён, но со сторонниками пророка Мухаммеда, которых в стране насчитывается более 5 млн, обстоит сложнее. Само понятие свободы вероисповедания трактуется в мусульманской среде по-разному: одни (умеренные) готовы признать приоритет и незыблемость принципов Республики, исповедуя свою религию в очерченных законами рамках (дома и в специально отведённых местах), а другие (радикалы, исламисты) - настаивают на «своём неотъемлемом праве» не только воздействовать религиозными постулатами на общественную жизнь во Франции, но и в каких-то случаях подчинять её «требованиям Корана». Найти компромисс, расставляющий акценты в этой системе коорди-

(C) Шумилин Александр Иванович - доктор политических наук, главный научный сотрудник, руководитель центра «Европа - Ближний Восток» Отдела европейской безопасности, главный редактор Научно-аналитического вестника ИЕ РАН. Адрес: 125009, Россия, Москва, ул. Моховая, д. 11, стр. 3. E-mail: mideast@bk.ru.

Статья поступила в редакиию: 20.04.2021.

${ }^{1}$ Шумилин А. Франция: Республика против «политического ислама» (ч. I) // Научно-аналитический вестник ИЕ PAH. 2021. №1. C. 54-61. DOI: 10.15211/vestnikieran120215461 
нат, призвана предложенная правительством «Хартия Принципов». Её принятие руководством исламских организаций власти рассматривают как основание для продолжения их финансирования со стороны государства. Документ из 10 пунктов назван Макроном «основополагающим текстом для определения отношений между Государством, Исламом и Францией» ${ }^{1}$. В нём выделяется особая значимость такого постулата, как отделение религии от государства и перечисляется целый ряд необходимых, с точки зрения правительства, мер 2 .

Дебаты в верхней палате, однако, развивались по несколько иной траектории: многие сенаторы сочли недостаточными предложения правительства и приняли решения/рекомендации, которые не только радикалы, но и часть умеренных в мусульманской среде называют проявлением исламофобии. Чтобы снять остроту возникшей проблемы, правительство намерено вернуть спорный документ в Национальное собрание, которое по конституции утверждает окончательную версию любого законопроекта.

\section{Сенат и проблема «исламофобии»}

Обсуждение правительственной инициативы о «борьбе с сепаратизмом» в обеих палатах парламента не только обозначило остроту самой проблемы политизации ислама в стране, но и отразило отношение к ней во французском обществе. Так, если при голосовании в Национальном собрании 16 февраля треть депутатов (а с учётом воздержавшихся и больше трети) сочли законопроект дискриминирующим мусульманскую общину страны, то две трети сенаторов (208 против 109) наоборот назвали предложенные правительством меры недостаточными. И предпочли ужесточить законопроект посредством внесения в него весьма резонансных и болезненных для мусульманского сообщества дополнений. В результате обе палаты, по сути, вступили в противостояние по данной проблеме, а правительство и президент стараются играть роль посредников между ними. Иными словами, сам законопроект и его авторы уже не выглядят «ярыми исламофобами» в глазах сторонников тех мусульманских организаций, которые отказались принять упомянутую «Хартию принципов» ${ }^{3}$. Теперь их гнев обращен против сенатского большинства.

Утверждённые верхней палатой 12 апреля дополнения в правительственный законопроект заметно ужесточают его изначальную версию. Так, например, они расширяют законодательно оформленный ещё в 2004 г. запрет на демонстрацию религиозных символов, включая ношение в школах одежды, указывающей на принадлежность к определённой вере 4 . Теперь, по идее сенаторов, не должны закрывать свои лица не только школьники, но и сопровождающие их взрослые при выходе за пределы учебных заведений, во время спортивных мероприятий и т.д. Кроме того, декларируется запрет на ношение в общественных бассейнах сплошных купальников (burkini), дискриминирующих женщин по отношению к мужчинам. Сенаторы от президентской партии «Республика на марше» воздержались при голосовании по этим позициям, а глава МВД Ж. Дарманин подчеркнул, что правительство не согласно с предло-

\footnotetext{
${ }^{1}$ Fight against separatism - the Republic in action: speech by Emmanuel Macron, President of the Republic, on the fight against separatism (Les Mureaux, 02 Oct. 2020). The Ministry for Europe and Foreign Affairs (MEAE). 02.10.2020. URL: https://www.diplomatie.gouv.fr/en/coming-to-france/france-facts/secularism-and-religious-freedom-in-france-63 815/article/fight-against-separatism-the-republic-in-action-speech-by-emmanuel-macron (дата обращения 15.01.2021). 2 Bermingham P.-P. France issues charter for imams meant to fight «political Islam». Politico. 18.01.2021. URL: https://www.politico.eu/article/france-political-islam-charter-imams-fight/ (дата обращения 20.01.2021).

3 Это три организации, действующие в мусульмано-турецкой общине - Координационный комитет турецких мусульман во Франции (ККТМФ), Исламская конфедерация Милли Горюс (ИКМГ) и Движение за веру и практику (ДВП). См. подробнее: Шумилин А.И. Франция: Республика против «политического ислама» (ч. I) ...

${ }^{4}$ Principes de la République. Lundi 12 avril 2021, le Sénat a adopté avec modifications le projet de loi confortant le respect des principes de la République et de lutte contre le séparatisme. Senat. 12.04.2021. URL: http://www.senat.fr/es pace_presse/actualites/202101/principes_de_la_republique.html\#c660552 (дата обращения 22.04.2021).
}

Научно-аналитический вестник ИЕ РАН, 2021, №2 
женным запретом выражать религиозную принадлежность граждан в общественных местах ${ }^{1}$. Сенатское большинство требует вывести религиозные практики (моления) за пределы помещений государственных высших учебных заведений и «других не предназначенных для этого мест» ${ }^{2}$.

В сфере политики сенаторы предлагают запретить ведение избирательных кампаний на основе платформ, противоречащих идеям «национального суверенитета, демократии и светскости», запретить потенциальным кандидатам, демонстрирующим религиозные символы, участие в выборах и публичных мероприятиях. Иммиграционные власти наделяются правом не возобновлять разрешения на пребывание в стране лицам, отвергающим республиканские принципы, а социальные службы - правом отказывать в предоставлении льгот семьям в случае частых пропусков детьми занятий в школах в пользу домашнего обучения ${ }^{3}$. Показательно, что сенаторы левого толка, а также правозащитные группы выступили против одобренной верхней палатой версии законопроекта. Критиков поддержал и национальный филиал Amnesty International France $(A I F)^{4}$.

\section{«Братья-мусульмане» идут ва-банк}

Насколько правительству и президенту удастся в ближайшие недели исполнять функцию посредника между двумя палатами парламента - большой вопрос. Дело в том, что решение сената лишь подлило масла в уже полыхающий огонь дискуссий вокруг положения в мусульманских общинах и вокруг них. Острые дебаты развернулись на всех уровнях - от низового (внутри и межобщинного) до «элитного». Примером последнего следует считать происходящее в академических кругах: представители правительства, включая министра высшего образования Ф. Видаль, ещё в середине февраля (накануне обсуждения законопроекта в нижней палате) публично обозначили противниками своей политики некие группировки в академической среде, идеи которых основываются на слиянии/синтезе «исламизма и левачества » (Islamo-leftism, «исламо-левачество») ${ }^{5}$. Особенно резонансно прозвучало высказывание Видаль о том, что «"исламо-левачество" подрывает всё общество, включая университеты» ${ }^{6}$. Представители академического сообщества ощутили себя «объектом атаки со стороны правительства». Они отвергли подобные утверждения, объяснив их попытками партии Макрона дискредитировать своих политических оппонентов в преддверии предстоящих в 2022 г. президентских выборов. Иными словами, они считают, что команда президента намеренно обостряет ситуацию вокруг мусульманских общин Франции с целью прежде всего подорвать позиции левых в обществе, акцентируя «исламистскую угрозу» ${ }^{7}$.

\footnotetext{
${ }^{1}$ French Senate approves toughened version of bill accused of stigmatising Islam. RFI. 13.04.2021. URL: https://www. rfi.fr/en/france/20210413-french-senate-approves-toughened-version-of-bill-accused-of-stigmatising-islam-religionmuslims (дата обращения 20.04.2021).

2 Ibid.

${ }^{3}$ Ibid.

${ }^{4}$ France / Projet de loi confortant le respect des principes de la République. Amnesty International France condamne un texte discriminatoire et demande le retrait des dispositions contraires au droit international. Amnesty International France. 13.04.2021. URL: https://www.amnesty.fr/presse/amnesty-international-france-aif-exprime-ses-plus (дата обращения 22.04.2021).

5 Сам этот термин был запущен в оборот Пьером-Андре Тагиефф, автором монографии «Новая юдофобия» (2002), в которой он обосновал партнёрство между исламистами и леваками в Европе их общим стремлением противодействовать израильской оккупации в период второй палестинской интифады (начало 2000-х гг.).

${ }^{6}$ Soazig Le Nevé. Frédérique Vidal lance une enquête sur «l'islamo-gauchisme» à l'université. Le Monde. 16.02.2021. URL: https://www.lemonde.fr/societe/article/2021/02/16/frederique-vidal-lance-une-enquete-sur-l-islamo-gauchisme-a1-universite_6070195_3224.html (дата обращения 20.04.2021).

${ }^{7}$ Chloé Benoist. France: What is the «Islamo-leftism» debate really about? MiddleEastEye. 05.03.2021. URL: https:// www.middleeasteye.net/news/france-islam-leftism-macron-muslims-academia-elections (дата обращения 23.04.2021).
}

Научно-аналитический вестник ИЕ РАН, 2021, №2 
В само́й мусульманской среде Франции обсуждения законопроекта против сепаратизма дали повод для активизации радикалов и исламистов, против которых, собственно, и направлена инициатива правительства. Помимо уже упомянутых трёх крупных мусульманских организаций, отказавшихся подписать Хартию, в начале марта образовалась ещё одна группа их единомышленников, которая назвала себя «Международной коалицией против исламофобии» (МКПИ). Большинство участников этой группы называют себя французами, хотя на самом деле не имеют гражданства этой страны. 8 марта 2021 г. они направили главе Еврокомиссии Урсуле фон дер Ляйен обращение с осуждением «исламофобских законов Франции».

Публикация этого письма вызвала возмущение немалой части французского общества: авторы лишь упоминают террористические акты исламистов (включая обезглавливание учителя Самуэля Пати) без явного осуждения их, и при этом расценивают антитеррористические операции властей как «репрессии в отношении мусульман» ${ }^{1}$ В своём обращении к главе Еврокомиссии они утверждают, что «юридическая система Франции не предоставляет никаких реальных и эффективных способов остановить претворение в жизнь правительством этой страны структурной и системной исламофобии». И настаивают на вмешательстве наднациональных органов ЕС, чтобы обеспечить права мусульман и оградить их от исламофобии и других форм ненависти ${ }^{2}$.

Не удивительно, что ряд ведущих европейских экспертов охарактеризовали появление данного обращения как проявление экстремизма. Информация из накопленной базы данных проливает свет на связь авторов письма с европейской ветвью международной исламистской ассоциации «Братья-мусульмане» $(\text { БМ })^{3}$. Парадокс, однако, в том, что на Ближнем Востоке она запрещена в арабских монархиях Персидского залива, Египте и Сирии, но является влиятельной силой в таких странах, как Катар, Турция, Тунис. За пределами этого региона она квалифицируется как террористическая в России и ряде стран СНГ, но не в Европе и США. Реальностью последних лет стало обостряющееся противостояние вокруг БМ между арабскими монархиями залива во главе с Саудовской Аравией и Турцией. До последнего времени Катар в этом конфликте был намного ближе к Турции, чем к монархиям ${ }^{4}$.

Такое противостояние отчётливо проецируется на мусульманские общины в странах Европы, особенно во Франции: если Турция и Катар поддерживают организации, исповедующие идеологию «братьев», то Саудовская Аравия и другие монархии, а также Египет стремятся представить их потенциальной угрозой для политической стабильности Евросоюза. Проекция ближневосточного противоборства вокруг БМ особенно заметна в интеллектуальной, университетской среде Франции, на которую упомянутые протагонисты стремятся оказывать влияние через спонсирование всякого рода исследовательских центров и даже целых факультетов. Отчётливо просматривается она и в политическом пространстве страны. Так, если вышеприведённое обращение МКПИ к руководству ЕС поддержали не только отдельные деятели, но и организации, спонсируемые из Турции, то, например, финансируемый из Саудовской Аравии исследовательский центр Эль-Месбар (Al-Mesbar Studies \& Research Center) продвигает иную точку зрения, которая, заметим, весьма положительно воспринимается правыми и центристскими силами во Франции. Так, в изданной в марте 2019 г. этим центром монографии подчёркивается, что «существование во Франции организационных структур исламистских

\footnotetext{
${ }^{1}$ Islamist Lawfare against the European Union. European Eye on Radicalization. 12.04.2021. URL: https://eeradicaliza tion.com/islamist-lawfare-against-the-european-union/ (дата обращения 21.04.2021).

${ }^{2}$ Ibid.

${ }^{3}$ Ibid.

${ }^{4}$ Шумилин А. Ближневосточные конфликты сегодня: между религией и геополитикой // Мировая экономика и международные отношения. 2021. Т. 65. №1. С. 50-60. DOI: 10.20542/0131-2227-2021-65-1-50-60
}

Научно-аналитический вестник ИЕ РАН, 2021, №2 
движений создаёт прямую угрозу национальной безопасности страны. Сторонники политического ислама прибегают к такому риторическому стилю, который выглядит прагматическим, но на самом деле является радикальным и подрывным. На протяжении десятилетий они стремились создать себе твёрдую базу поддержки, игнорируя уникальный характер других обществ, как и их естественную траекторию развития» 1 .

Просаудовские «мозговые центры» взяли на себя миссию разоблачать деятельность во Франции (и во всей Европе) организаций, связанных с БМ и, соответственно, с Турцией. Так, аналитики этой направленности подчёркивают, что одна из важнейших особенностей «братьев» состоит в их способности адаптироваться к самым разным социально-политическим условиям, в том числе и в странах с режимом электоральной демократии (концепция БМ основана на предпочтительности выборных механизмов при формировании структур управления государством, а не на передаче власти по наследству) ${ }^{2}$. Во многом им это удаётся за счёт замалчивания (silence tactics) реальных целей группировки (а именно - построения исламского государства на основе шариата) и переноса акцентов на благотворительную и просветительную деятельность, на отстаивание прав мусульман в странах Запада исповедовать свою религию. Это делается через систему организаций, формально не связанных с БМ, но исповедующих их идеологию.

В середине ноября 2020 г. Совет старших улемов Саудовской Аравии (Saudi Council of Senior Scholars) сделал специальное заявление по ситуации вокруг БМ в Европе. По их мнению, эта организация «не представляет ислам, а угрожает ему в той же мере, что и Европе в целом, из-за того, что последняя привечала “братьев” на протяжении десятилетий, позволяя им контролировать мечети и мусульманские сообщества» ${ }^{3}$. При этом старейшины подчеркнули, что позиция королевства относительно БМ не изменится даже после прихода в Белый дом администрации Джо Байдена, сподвижника Б. Обамы, якобы благоволившего «братьям» ${ }^{4}$

Если в интеллектуальных кругах Франции по-прежнему ведутся дискуссии вокруг соотношения степеней «умеренности» и «радикальности» БМ, то эксперты и политики всё чаще определяют родственные «братьям» структуры как экстремистские вне отношения между правительством и мусульманскими организациями, опекаемыми Турцией, продолжают обостряться. В конце марта 2021 г. разразился скандал из-за строительства мечети в Страсбурге, которая, как выяснилось, находится под контролем Исламской конфедерации Милли Горюс (ИКМГ), одной из трёх крупных организаций, действующих в турецкой общине и отказавшейся подписать «Хартию Принципов». Проблема в том, что возглавляемый «зелёным» мэром муниципалитет выделил ИКМГ на строительство грант в 2,5 млн евро. Глава МВД Ж. Дарманин заявил в этой связи следующее: «Мы полагаем, что эта ассоциация более не может представлять ислам во Франции, а муниципальные власти не должны финансово поддерживать иностранное вмешательство в наши дела» 6 .

Напомним, что на фоне расхождений между Анкарой и Парижем в подходе к таким кон-

\footnotetext{
${ }^{1}$ Islam in France: The Brotherhood, Terrorism, and Treatment. Dubai. 2019. URL: https://mesbar.org/islam-in-francethe-brotherhood-terrorism-and-treatment/ (дата обращения 12.04.2021).

${ }^{2}$ Царегородцева И.А. Политико-правовые концепции идеологов египетского движения «Братья-мусульмане» // Учёные записки Казанского университета. Серия Гуманитарные науки. 2013. Т. 155. Кн. 3. Ч. 2. C. 98-110. URL: https://publications.hse.ru/mirror/pubs/share/folder/304zkhkq6m/direct/101162314.pdf (дата обращения 14.04.2021).

${ }^{3}$ Saudi Arabia tells Europe: The Muslim Brotherhood is a threat to Islam. The Arab Weekly. 12.11.2020. URL: https://thearabweekly.com/saudi-arabia-tells-europe-muslim-brotherhood-threat-islam (дата обращения 14.04.2021). ${ }_{5}^{4}$ Ibid.

Tarik Ali Ahmad. Muslim Brotherhood's danger dawns on France. Arab News. 14.07.2020. URL: https://www.arabnews.com/node/1704676/world (дата обращения 24.04.2021).

${ }^{6}$ Row erupts in France over state funding for Turkish mosque. Arab news. 24.03.2021. URL: https://www.arabnews. com/node/1832321/world (дата обращения 20.04.2021).
}

Научно-аналитический вестник ИЕ РАН, 2021, №2 
фликтам, как в Ливии, Сирии и Нагорном Карабахе, турецкий президент всё чаще подвергает критике политику Макрона в отношении французских мусульман. Не удивительно, что Эрдоган пытается защищать и продвигать позиции трех упомянутых исламских (а точнее - исламистских) организаций во Франции, исповедующих, как и он сам, идеологию «Братьев-мусульман». В этой связи Макрон предупредил своего турецкого визави от попыток вмешательства в президентские выборы в 2022 г.

$* \quad * \quad *$

Мусульмане во Франции переживают в настоящее время один из самых драматических периодов своей истории. По настоянию властей они должны, по сути, чётко сформулировать: готовы ли они стать полноценными гражданами, исповедующими ислам, но признающими приоритет принципов, на которых основана Французская республика, или они ставят свою мусульманскую идентичность выше конституции и норм страны проживания. Две трети крупных мусульманских организаций поддержали инициативу президента Макрона, подписав «Хартию Принципов». Но три ассоциации, не скрывающие своих связей с Турцией и исповедующие идеологию «Братьев-мусульман», судя по всему, не готовы жить по правилам Республики. В этом их достаточно открыто поддерживает президент Р.Т. Эрдоган, пытающийся в своих интересах использовать сложную ситуацию вокруг мусульманских сообществ во Франции. В «борьбе за умы мусульман» власти Франции получают поддержку со стороны, прежде всего, монархий Персидского залива и других арабских стран, твёрдо выступающих против распространения влияния группировки «братьев» в ближневосточном регионе и за его пределами, в частности в Европе.

\section{Список литературы}

Новоженова И.С. Франция: Ислам в светском государстве // Актуальные проблемы Европы. 2008. №1. С. 130-145.

Потемкина О.Ю. Европейский союз: война с терроризмом не окончена // Научно-аналитический вестник ИЕ РАН. 2020. №1. DOI: 10.15211/vestnikieran120202935

Царегородцева И.А. Политико-правовые концепции идеологов египетского движения «Братья-мусульмане» // Учёные записки Казанского университета. Серия Гуманитарные науки. 2013. Т. 155. Кн. 3. Ч. 2. C. 98-110. URL: https://publications.hse.ru/mirror/pubs/share/folder/304 zkhkq6m/direct/101162314.pdf (дата обращения 26.04.2021).

Шумилин А.И. Ближневосточные конфликты сегодня: между религией и геополитикой // Мировая экономика и международные отношения. 2021. Т. 65. №1. С. 50-60. DOI: 10.20542/0131-2227-2021-65-1-50-60

Шумилин А.И. Франция: Республика против «политического ислама» (Ч. І) // Научноаналитический вестник ИЕ РАН. 2021. №1. С. 54-61. DOI: 10.15211/vestnikieran120215461

Шумилин А.И. Евросоюз-Турция: конфликтное партнёрство // Научно-аналитический вестник ИЕ РАН. 2020. №5. С. 7-15. DOI: 10.15211/vestnikieran320194853

\section{References}

Bermingham, P.-P. (2021). France issues charter for imams meant to fight «political Islam». Po-

\footnotetext{
${ }^{1}$ Macron warns against Turkish «interference» in French presidential election. Euronews. 24.03.2021. URL: https:// www.euronews.com/2021/03/24/macron-warns-against-turkish-interference-in-french-presidential-election (дата обращения 26.04.2021).
}

Научно-аналитический вестник ИЕ РАН, 2021, №2 
litico. January 18, 2021. Available at: https://www.politico.eu/article/france-political-islamcharterimams-fight/ (accessed 20.01.2021).

Caregorodceva, I.A. (2013). Politiko-pravovye koncepcii ideologov egipetskogo dvizheniya «Brat'ya-musul'mane» [Political and legal concepts of the ideologists of the Egyptian Muslim Brotherhood movement]. Uchenye zapiski Kazanskogo universiteta. Seriya Gumanitarnye nauki [Proceedings of Kazan University. Humanities Series]. Vol. 155. Book 3. Chapter 2. P. 98-110. Available at: https://publications.hse.ru/mirror/pubs/share/folder/304zkhkq6m/direct/101162314.pdf (accessed 20.01.2021).

Fight against separatism - the Republic in action: speech by Emmanuel Macron, President of the Republic, on the fight against separatism. The Ministry for Europe and Foreign Affairs (MEAE). October 2, 2020. Available at: https://www.diplomatie.gouv.fr/en/coming-to-france/france-facts/sec ularism-and-religious-freedom-in-france-63815/article/fight-against-separatism-therepublic-in-actio n-speech-by-emmanuel-macron (accessed 15.01.2021).

France / Projet de loi confortant le respect des principes de la République. Amnesty International France condamne un texte discriminatoire et demande le retrait des dispositions contraires au droit international. Amnesty International France. April 13, 2021. Available at: https://www.amnesty.fr/ presse/amnesty-international-france-aif-exprime-ses-plus (accessed 22.04.2021).

French Senate approves toughened version of bill accused of stigmatising Islam. RFI. April 13, 2021. Available at: https://www.rfi.fr/en/france/20210413-french-senate-approves-toughened-versio n-of-bill-accused-of-stigmatising-islam-religion-muslims (accessed 20.04.2021).

Novozhenova, I.S. (2008). Francija: Islam v svetskom gosudarstve [France: Islam in secular state]. Aktual'nye problemy Evropy [Current problems of Europe]. 1. P. 130-145. (In Russian).

Potemkina, O.Yu. (2020). Evropejskij sojuz: vojna s terrorizmom ne okonchena [European Union: the war with terrorism is not over]. Nauchno-analiticheskij vestnik IE RAN [Scientific and Analytical Herald of the IE RAS]. 1. P. 29-35. (In Russian). DOI: 10.15211/vestnikieran120202935

Principes de la République. Lundi 12 avril 2021. Le Sénat a adopté avec modifications le projet de loi confortant le respect des principes de la République et de lutte contre le séparatisme. Senat. April 12, 2021. URL: http://www.senat.fr/espace_presse/actualites/202101/principes_de_la_republi que.html\#c660552 (accessed 19.04.2021).

Shumilin, A.I. (2020). Evrosojuz-Turcija: konfliktnoe partnjorstvo [European Union - Turkey: Conflict Partnership]. Nauchno-analiticheskij vestnik IE RAN [Scientific and Analytical Herald of the IE RAS]. 5. P. 7-15. (In Russian). DOI: 10.15211/vestnikieran320194853

Shumilin, A.I. (2021). Blizhnevostochnye konflikty segodnya: mezhdu religiej i geopolitikoj. [Middle East conflicts today: between religion and politics]. Mirovaya ekonomika i mezhdunarodnye otnosheniya [World economy and international relations]. Vol. 65, no. 1. P. 50-60. (In Russian). DOI: 10.20542/0131-2227-2021-65-1-50-60

Shumilin, A.I. (2021). Franciya: Respublika protiv «politicheskogo islama» (Ch. I) [France: Republic against «Political Islam»(Part I)]. Nauchno-analiticheskij vestnik IE RAN [Scientific and Analytical Herald of the IE RAS]. 1. P. 54-61. (In Russian). DOI: 10.15211/vestnikieran120215461

\section{France: Republic against «Political Islam» (Part II)}

Author. Alexander Shumilin, Doctor of Political Sciences, Chief Research Associate, Head of the Center «Euro-Atlantic - the Middle East» of the European Security Department, Editor -in Chief of the Scientific Analytical Herald at the Institute of Europe, Russian Academy of Sciences. Address: 11-3, Mokhovaya str., Moscow, Russia, 125009. E-mail: mideast@ bk.ru. 


\begin{abstract}
From March 30 to April 12, 2021, members of the French Senate considered the government-prepared draft law on «countering separatism». His ideology is primarily aimed at curbing the increased activity of supporters of «political Islam» (Islamism) in France. Earlier, on February 16, 2021, the National Assembly (lower house of parliament) had approved the document. As shown in the first part of the article, the discussion of the draft deepened the split in the Muslim community of France between followers of moderate Islam, who supported the efforts of the government, and Islamists, who rejected the main provisions of the document. This article attempts to analyze a new stage of relations between the state and the Muslim community of the country against the background of the decisions made by the senators. Accusing the French government of «Islamophobia»", Islamic radicals appeal to the leadership of the European Union. Behind them, the figure of the Turkish President R.T. Erdogan, who is increasingly using religious rows in Europe for his own political purposes. The author of the article comes to the conclusion that the escalating confrontation in the Muslim environment and around it is acquiring more and more obvious political implications in France.
\end{abstract}

Key words: France, Muslims, Islam, political Islam, Turkey, Saudi Arabia, Erdogan, Macron, Charter of Principles, Darmanin

DOI: http://dx.doi.org/10.15211/vestnikieran22021117124 